\title{
Ultrasonography of the Diagnosis the Degenerative-Dystrophic Changes in the Vertebral Motor Segment as a Potential Cause of Back Pain: Pictorial Essay
}

\author{
Rizvan Abdullaiev ${ }^{1^{\star}}$, Rostyslav Bubnov ${ }^{2,3}$, Vitaliy Tsymbalyuk ${ }^{4,5}$, Olena Grechanyk ${ }^{6}$, Lev Kalika ${ }^{7}$ and Zbigniew Pilecki $^{8,9}$ \\ ${ }^{1}$ Department of Ultrasound Diagnostics, Kharkiv Medical Academy of Postgraduate Education, Ukraine \\ ${ }^{2}$ Clinical Hospital, 'Pheophania' of State Affairs Department, Ukraine \\ ${ }^{3}$ Zabolotny Institute of Microbiology and Virology, NAS of Ukraine \\ ${ }^{4}$ Department of Neurosurgery of the Bogomolets, National Medical University, Kyiv, Ukraine \\ ${ }^{5}$ National Academy of Sciences of Ukraine, Ukraine \\ ${ }^{6}$ Department of Ultrasound Diagnostics of the National Military Medical Clinical Center, Main Military Clinical Hospital, Kyiv, Ukraine \\ ${ }^{7}$ New York Dynamic Neuromuscular Rehabilitation and Physical Therapy, New York, USA \\ ${ }^{8}$ Department of Orthopedics and Traumatology of Locomotor System for Children, Chorzyw, Poland \\ ${ }^{9}$ Department of Orthopedics and Traumatology of Sports Medicine Center, Zabrze, Poland
}

*Corresponding author: Abdullaeiv RY, Department of Ultrasound Diagnostics, Kharkiv Medical Academy of Postgraduate Education, Ukraine, Tel: +380972371919; Email: r.abdullaev@bk.ru

Rec Date: September 11, 2017; Acc Date: October 24, 2017; Pub Date: October 29, 2017

Copyright: (c) 2017 Abdullaev RY, et al. This is an open-access article distributed under the terms of the Creative Commons Attribution License, which permits unrestricted use, distribution, and reproduction in any medium, provided the original author and source are credited.

\begin{abstract}
The topical diagnosis and determination of the mechanism of pain of vertebrogenic origin remain the actual problems of medicine. This is due to the difficulty in differential diagnosis, the high incidence of occurrence, the severity of clinical manifestations of the spinal column pathology and their consequences, and the anatomical features of the structure of the vertebrae. From the clinical point of view, the solution to the problem of vertebrogenic pain involves a number of aspects: The definition of the source of pain, the establishment of its mechanisms and paths for its elimination. Thus, ultrasonography is effective for the diagnosis the degenerative-dystrophic changes in the vertebral motor segment as a potential cause for pathophysiological mechanism of back pain.
\end{abstract}

Keywords: Vertebrogenic; Pathology; Chronic; Ultrasonography; Hernia

\section{Introduction}

Most elements of the human vertebral column contain nerve endings, the irritation of which can be a source of pain. Free nerve endings that perform the function of pain receptors are found in capsules of the apophysic (facet) joints, posterior longitudinal, yellow, interosseous bundles, solid cerebellum, epidural fatty tissue, periodontal vertebrae, arteriolar and vein walls, paravertebral muscle vessels, outer third of the fibrous ring of intervertebral disc. Any of the listed above structures may be involved in the pathological process.

Among the causes of vertebrogenic pain, the degenerativedystrophic changes in the vertebral motor segment are significant. They also lead to the development of protrusion and hernia of the intervertebral disc, stenosis of the vertebral canal, instability of the vertebral motor segment, spondylolisthesis. The intensity and localization of the pain depend on the mechanism of irritation (irrigation) of the nerve receptors in the zone of the altered intervertebral disc. In the same patient with chronic changes in the vertebral motor segment, the immediate cause of pain may be different in each particular case. With the advent and further development of MRI and ultrasound, the ability to evaluate soft tissue structures, in particular, the vertebral motor segment was expanded. It is known that degenerative changes in the intervertebral disc are observed more often than the damage to the vertebral bodies. Ultrasonography allows to evaluate the condition of all elements of the vertebral motor segment.

\section{Data and Methods}

This contribution summarizes previously published data [1-5] presenting relevant illustrative material to demonstrate the capabilities of ultrasonography to detect the degenerative-dystrophic changes in the vertebral motor segment as a potential cause of back pain. All the figures presented are the original ultrasonograms (USG) performed at the cervical and lumbar levels in longitudinal and transverse projections in patients with back pain [6-10].

\section{Results and Discussion}

Comparison of clinical symptoms and ultrasonography results in patients with potentially vertebrogenic pain allowed to detect a certain correlation between them. For example, among people with cervical gland, frequent ultrasound findings are a moderate heterogeneity of the pulp nucleus, an increase in its echogenicity, especially at the boundary of the fibrous ring, the compression and fracture of the latter. In patients with spondylogeneic radiculosismia, a disc hernia with the development of deformation and stenosis of the central vertebral column, as well as the root canals at the level of the affected intervertebral disc is often detected (Figures 1 and 2). 
Citation: Abdullaeiv RY, Bubnov R, Tsymbalyuk V, Grechanyk O, Kalika L, et al. (2017) Ultrasonography of the Diagnosis the DegenerativeDystrophic Changes in the Vertebral Motor Segment as a Potential Cause of Back Pain: Pictorial Essay . J Spine 6: 394. doi: 10.4172/2165-7939.1000394

Page 2 of 7

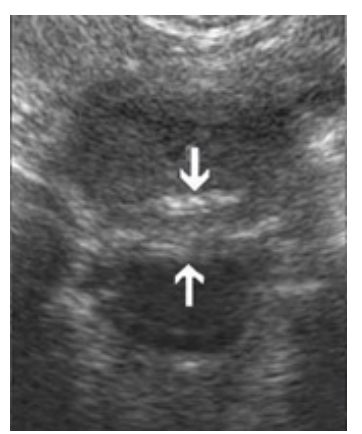

Figure 1: Echogram of intervertebral $\mathrm{C} 4-\mathrm{C} 5$ disc in a patient with cervicogenic pain. The upper arrow shows the least pronounced calcification of the pulp nucleus, and the lower one - the deformation of the front dural space due to circular protrusion.

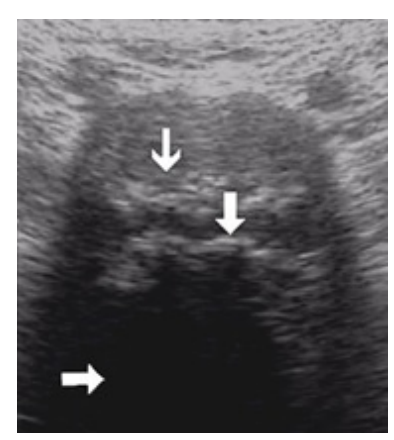

Figure 2: The patient has clinical manifestations of the shoulder and upper chest radiculitis. Advanced fibrosis of the C6-C7 disc with a large calcification of the pulp nucleus and the fibrous ring (upper arrows) with the presence of a dorsal acoustic shadow covering the image of the vertebral canal (lower arrow).

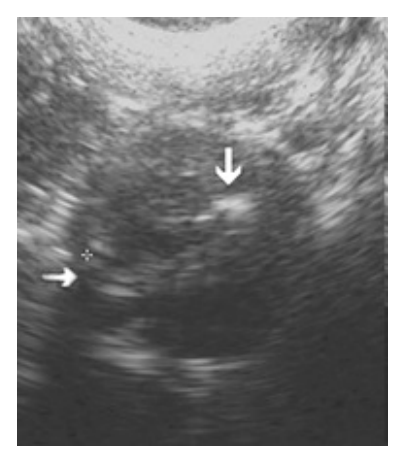

Figure 3: Echogram of $\mathrm{C} 2-\mathrm{C} 3$ intervertebral disc in a patient with prolonged neck pain, irradiation in the right shoulder, restriction of withdrawal and reduction of strength in the arm. The upper arrow shows focal calcification of the pulp nucleus, the right paramedian-foraminium hernia. Significant deformation of the front dural space and right root canal.
In the presence of a satisfactory ultrasound window, it is not difficult to detect fibrosis, hernia and disk protrusion, vertebral canal stenosis, spondylosis, spondylolisthesis, hypertrophy of the yellow ligament, the expansion of epidural veins, the scar and adhesion process in the epidural space, the instability of the vertebral-motor segment, the reactive epiduritis, which develop at the various stages of degenerativedystrophic process in the vertebral-motor segment (Figures 3 and 4).

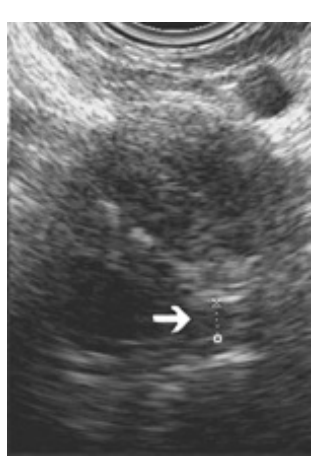

Figure 4: A similar clinical picture with left-sided localization. The arrow shows a foraminal hernia with a stenosis of the root canal.

We can distinguish several mechanisms of occurrence of irritative syndrome:

1) Mechanically compressive, when the protrusion and hernia of the disk or the crack directly affect the nerve root; 2) Mechanicallydisfacial, when irritation of the neural endings occurs when the fixation of the structures of the vertebral motor segment or displacements of the vertebrae is weakened; 3) Dyshemical, when irritation of afferent endings is caused by a violation of microcirculation in the tissues adjacent to the affected disk; 4) asepticinflammatory, when the irritation of the nerve fibers is due to inflammatory changes (epiduritis) in the structures of the vertebral motor segment (Figures 5 and 6).

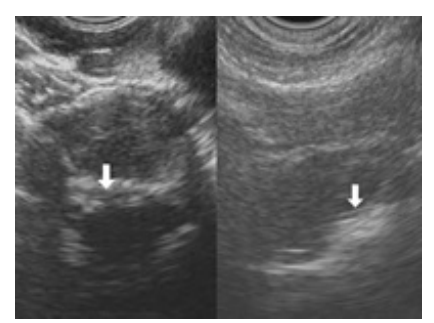

Figure 5: Visualization of the median paramedial hernia of the C4C5 intervertebral disc in a patient with a cervicogenic pain from the anterolateral (left arrow) and posterolateral access (right arrow). 
Citation: Abdullaeiv RY, Bubnov R, Tsymbalyuk V, Grechanyk O, Kalika L, et al. (2017) Ultrasonography of the Diagnosis the DegenerativeDystrophic Changes in the Vertebral Motor Segment as a Potential Cause of Back Pain: Pictorial Essay . J Spine 6: 394 . doi: 10.4172/2165-7939.1000394

Page 3 of 7

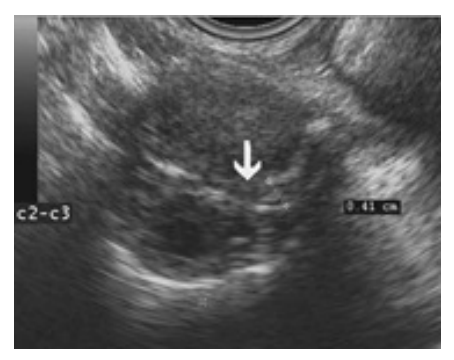

Figure 6: Echogram of intervertebral $\mathrm{C} 2-\mathrm{C} 3$ disc in patient with cervicogenic pain. The arrow shows a newly emerging hernia with a rupture of the fibrous ring and a stenosis of the root canal on the left.

Long-term traumatizing of the fibers of the fibrous ring at the levels of excessive physical load leads to its breakage and promotes the output of the pathological process beyond the disc (Figures 7 and 8).

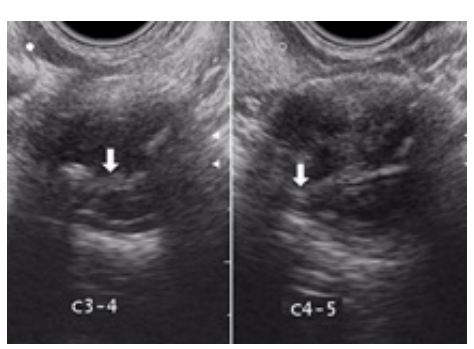

Figure 7: Patient demonstrtae a long-lasting pain in the collar area with spread to the right arm. Visualization of median hernia of C3C4 intervertebral disc with spinal stenosis (left arrow), right paramedian hernia C4-C5 with root canal stenosis (right arrow).

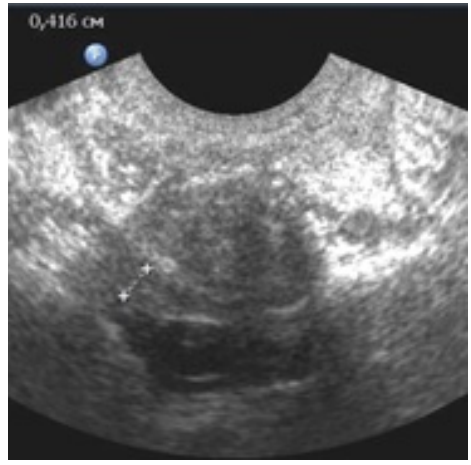

Figure 8: Large right-sided paramedian-foraminic hernia with smooth contour of intervertebral disc C4-C5 with moderate stenosis of the nerve root canal.

With the involvement of surrounding structures, which causes the most pronounced clinical symptoms. The break can occur at any location. The circles of the disk, however, the weakest parts of the fibrous ring are the posterior, where there are feeding vessels between the fibers in the process of intrauterine development (Figures 9 and $10)$.

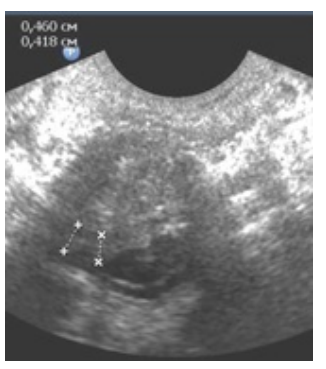

Figure 9: Large right-sided, predominantly paramedial, hernia with uneven contour of intervertebral disc C5-C6 with pronounced stenosis of the root canal.

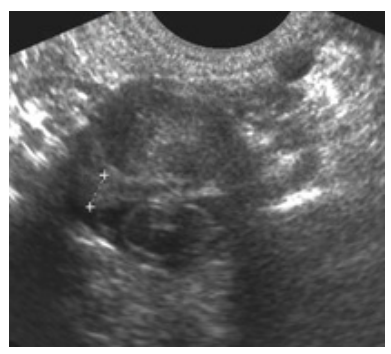

Figure 10: Combination of large right-sided paramedial hernia and median prothrussia $\mathrm{C} 4-\mathrm{C} 5$ with pronounced stenosis of the nerve root canal and compression of the front dural space.

There are several variants of the shape and direction of the rupture of the fibrous ring - from the simple radial to the complex course between the fibers, which sometimes flows into the vertebral canal almost at the edge of the disc, in this connection, the hernia of the disk may have an atypical arrangement (Figures 11 and 12).

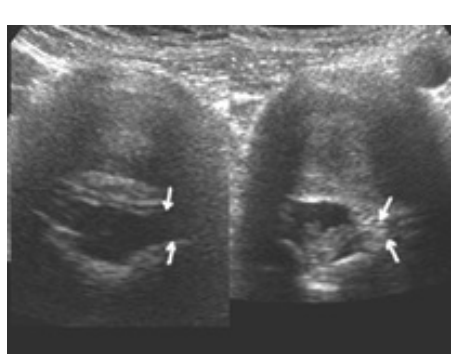

Figure 11: Echogram of intervertebral disc in a patient with pain in the left upper lumbar region. At the L2-L3 level, the root canals are symmetrical (left arrows), at the level L1-L2, a left-side paramedial protrusion with a stenosis of the root canal (right arrows). 
Citation: Abdullaeiv RY, Bubnov R, Tsymbalyuk V, Grechanyk O, Kalika L, et al. (2017) Ultrasonography of the Diagnosis the DegenerativeDystrophic Changes in the Vertebral Motor Segment as a Potential Cause of Back Pain: Pictorial Essay . J Spine 6: 394. doi: 10.4172/2165-7939.1000394

Page 4 of 7

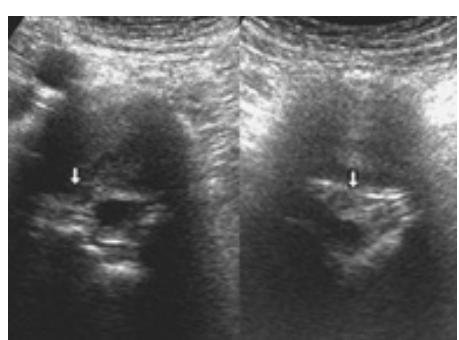

Figure 12: Echograms of intervertebral discs L3-L4 and L4-L5 in a patient with lumbar pain and irradiation in the right side of the pelvis and left leg. At the L3-L4 level, a large paramedial hernia with stenosis of the root canal (left arrow) is determined, at the level L4L5 - median paramedian hernia with stenosis of the central vertebral canal (right arrow).

One of the mobile fragments of the pulp cornea under the action of an axial load on the spine exits through the formed hole, forming a herniated disc. Dropping a fragment in the front or side of the disk does not lead to a conflict between it and the structures that play a significant role in the development of clinical manifestations, therefore such episodes are usually asymptomatic, disc hernias with such a localization - diagnostic findings. In the posterior parts of the disc, the dropped fragment usually ruptures a thin leaf of the posterior longitudinal ligament, without effort, into the epidural fiber, located adjacent to the veins of the epidural plexus, the solid cerebellum and the roots of the spinal cord (Figures 13 and 14).

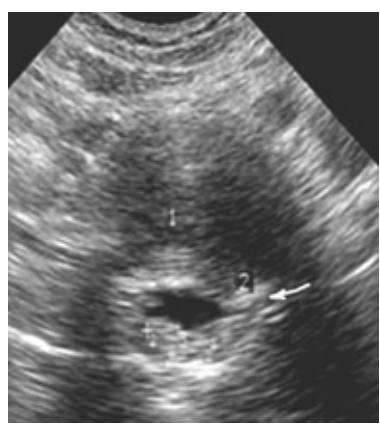

Figure 13: Echogram of intervertebral disc in a patient with pain in the left upper lumbar region. At the L1-L2 level, a left-sided paramedial hernia (2) with stenosis of the root canal (arrow) is determined.

Such injuries are usually associated with neurological symptoms of varying degrees of severity.

\section{Spinal canal stenosis}

Stenosis of the spinal canal is often observed in patients with a different localization of vertebrogenic pain. By the term "vertebral canal stenosis," a clinically significant reduction in the boundaries of the vertebral canal is determined. According to the etiologic principle, the dysplastic, degenerative, post-traumatic, and, according to localization, concentric, medial, lateral, and foraminal types of stenosis are distinguished (Figures 15 and 16).

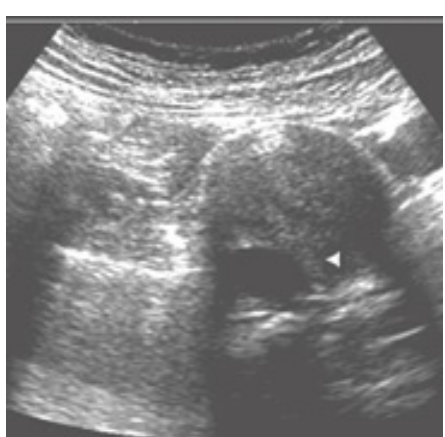

Figure 14: An echogram of an intervertebral disc in a patient with pain in the lumbar region with irradiation on the back surface of the left leg. At the L4-L5 level, a large left-sided paramedial hernia (arrow) with stenosis of the root canal is determined.

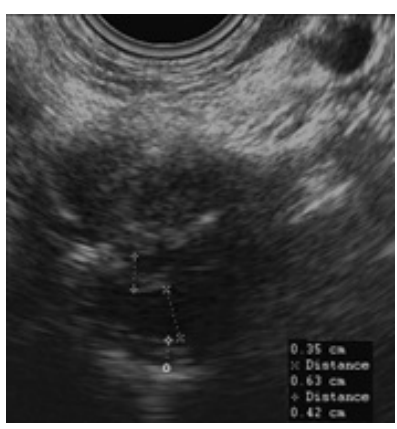

Figure 15: Stenosis of the spinal canal at the level of C4-C5, due to the right paramedial hernia. Prenatal size of the vertebral canal 0.63 $\mathrm{cm}$.

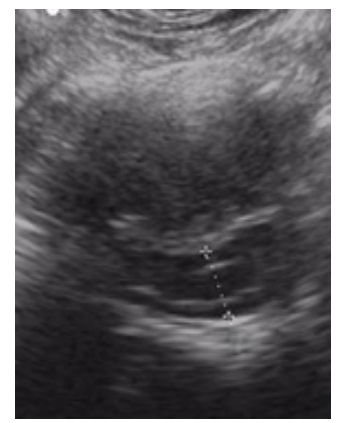

Figure 16: Stenosis of the spinal canal at the level of $\mathrm{C} 4-\mathrm{C} 5$, due to median hernia.

The most common causes of spinal stenosis are degenerative changes in the wall elements, as well as the displacement of the vertebrae. According to the anterior-posterior dimension of the cervical spine, three degrees of gravity of the stenosis can be distinguished: a) weak - $12-16 \mathrm{~mm}$; B) moderate $-10-12 \mathrm{~mm}$; C) expressed-less than $10 \mathrm{~mm}$ (Figures 17 and 18). 
Citation: Abdullaeiv RY, Bubnov R, Tsymbalyuk V, Grechanyk O, Kalika L, et al. (2017) Ultrasonography of the Diagnosis the DegenerativeDystrophic Changes in the Vertebral Motor Segment as a Potential Cause of Back Pain: Pictorial Essay . J Spine 6: 394. doi: $10.4172 / 2165-7939.1000394$

Page 5 of 7

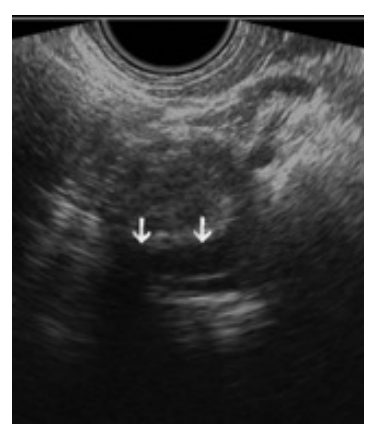

Figure 17: Stenosis of the spinal canal at the level of C5-C6, due to circular hernia.

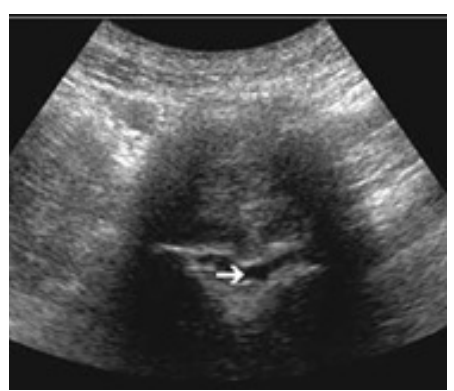

Figure 18: The expressed stenosis of the vertebral canal at the level of L4-L5 is due to circular hernia.

The stenosis variants according to the size of the vertebral canal are relative. Clinically, stenosis of the vertebral canal can be manifested with a decrease in its anterior-lateral size or transverse area so much that compression of the spinal cord occurs or irritation of the roots of the spinal nerves (Figures 19 and 20).

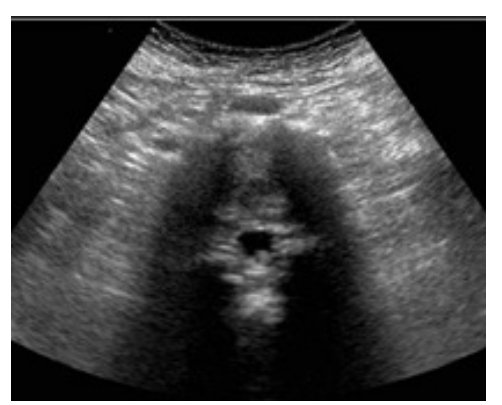

Figure 19: The expressed stenosis of the vertebral canal at the level of L3-L4 is due to the right paramedial hernia, left-sided paramedian protrusion, and hypertrophy of the yellow ligament.

The size and shape of the spinal canal and the channel of the cerebrospinal nerve depend on the degree of compression of the dural bag and nerve roots. Localization of hernia or protrusion determines the nature of the deformation of the vertebral and lateral channels.

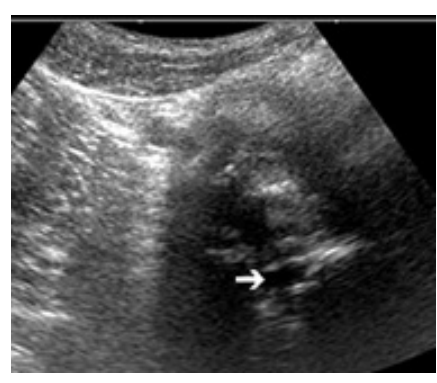

Figure 20: The expressed stenosis of the central vertebral and root canal L5-S1 is due to circular hernia.

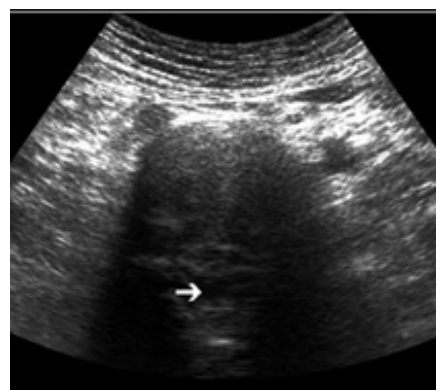

Figure 21: The advanced stenosis of the vertebral canal at the level of L4-L5 is due to circular hernia and hypertrophy of the yellow ligament.

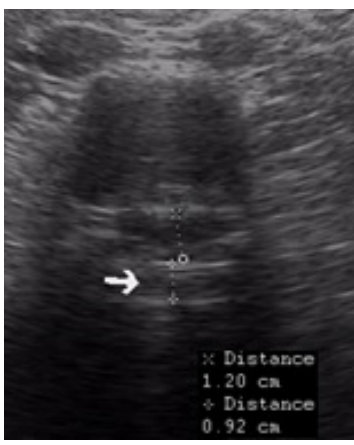

Figure 22: Stenosis of the vertebral canal is due to hypertrophy of the yellow bundle (arrow).

Median hernias and protrusions cause the maximum reduction of the anterior posterior size of the dural bag. The contraction of the latter, due to paramedical hernias and protrusions, is less pronounced than the median condition. The least vertebral canal deforms when posterolateral localization of a hernia or protrusion. At circular protrusions of disks, a simultaneous narrowing of the dural bag and lateral canals is observed, which is more often on the lumbar level. Foraminic and anterior hernias do not result in changes in the size of the dural bag and lateral root canals. Indirect signs of foraminal hernias are ruptures of fibrous rings at the level of intervertebral holes (Figures 21 and 22). 
Citation: Abdullaeiv RY, Bubnov R, Tsymbalyuk V, Grechanyk O, Kalika L, et al. (2017) Ultrasonography of the Diagnosis the DegenerativeDystrophic Changes in the Vertebral Motor Segment as a Potential Cause of Back Pain: Pictorial Essay . J Spine 6: 394 . doi: $10.4172 / 2165-7939.1000394$

Page 6 of 7

The development of hernia is always accompanied by an inflammatory process in the epidural fiber - epidurite. The phenomena of this disease can develop as at the time of the formation of the rupture of the fibrous ring, as well as when the hernia disappears. They distinguish between reactive and scar epiduritis. On the echogram, it manifests itself by the splitting of the boundary of the disk and the spinal canal with the visualization of hypo- and hyperechoic structures and displacement of the image of the front of the solid cerebellum in the direction of the vertebral canal and its contents (Figure 23).

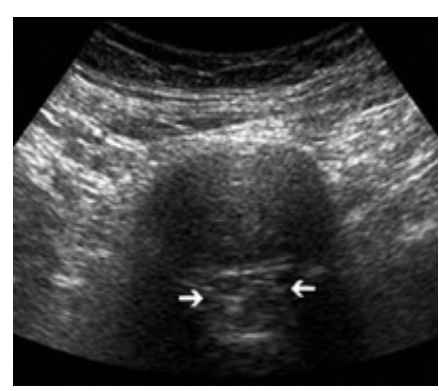

Figure 23: Paramedical hernia L4-L5, epidurite (arrows).

The reactive epiduritis develops at a very small sized hernial "focus". The protrusion of the posterior contour of the disc does not exceed 3 $\mathrm{mm}$. In such cases, a microscopic dropout of a pulp nucleus fragment usually occurs, which does not extend beyond the posterior longitudinal ligament (some authors call these hernias an extrusion) (Figure 24).

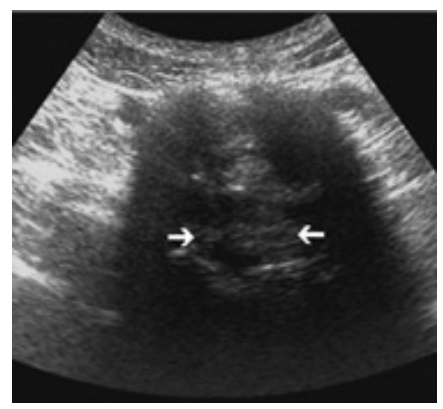

Figure 24: Deformed degenerative changes in the intervertebral disc L5-S1, circular hernia, epidurite (arrows).

Stubborn epiduritis is characterized by small splitting elements that form the posterior contour of the disc, without a clear hernial "focus", but with a sharp increase in the echogenicity of the posterior contour and epidural space. Such changes are formed with frequent exacerbation and, accordingly, conservative treatment of the inflammatory process or after surgical removal of the hernia. The presence of a hernia is usually indicated by the adjacent rupture of the fibrous ring. Signs of scar epiduritis can also be expressed in the presence of disc hernia criteria, usually in the region of its posterior contour. At the same time, they indicate a long and ineffective therapy, which did not lead to resorption of the hernia node (Figure 25).

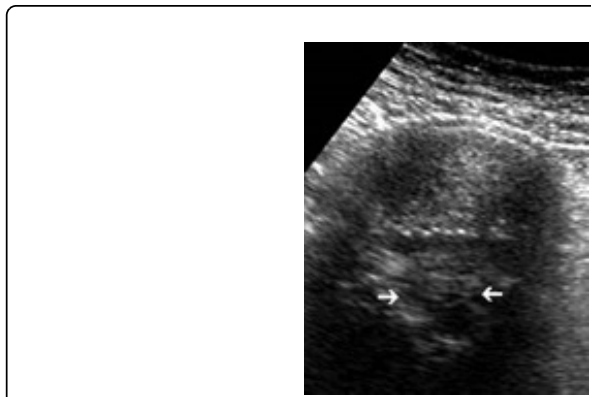

Figure 25: Significant degenerative changes in the intervertebral disc L4-L5, circular hernia, epiduritis (arrows).

\section{Degenerative-dystrophic changes in the ligament-articular apparatus}

The fibrous degeneration of the pulp nucleus and the destruction of the fibrous ring with the formation of a hernia are accompanied by pronounced degenerative changes in the ligament apparatus, the development of deforming arthrosis of articular joint with a rude reorganization of their synovial articular surfaces. In parallel, compensatory changes occur in the bodies of the vertebrae leading to the development of deforming spondylosis of varying degrees of severity. Due to the formation of coarse regional osteophytes, the bone surfaces of the vertebrae and the area of their contact widen. The formation of bone joints between osteophytes facilitates stabilization of the motor segment at different levels and limitation of mobility due to fibrous changes in the disk.

With ultrasound, the study of bone changes most often manifests itself in the form of osteophytes of different size and shape along the anterior contour of the vertebrae, bone create "bridges" between them.

During the ultrasound examination, it is important to determine the ratio of vertebrae. Normally, in sagittal section, the transitions of the front contour of the body of the vertebrae are smooth and interrupted.

\section{Intervertebral discs}

Degenerative-dystrophic changes in the intervertebral motor segment lead to displacement of vertebrae, which can be detected both in static examination and in the performance of functional tests. The displacement of vertebrate bodies relative to each other in the sagittal plane, detected by scanning from the front access, is called spondylolisthesis. Offsets of vertebral bodies forward are named as antelesthesis, and displacement as retrolistesis (Figure 26).

Pathological changes in articular processes and articular joint are manifested by spondyloarthrosis. The main ultrasonic criteria for sopandialarthrosis are the narrowing of the articular slit of the articular joint, fragmentation of subchondral plates, thickening and perifocal edema of the capsule of the joint, and the presence of marginal osteophytes. Usually clinically significant spondyloarthrosis, capable of causing compression of the roots, is characterized by onesided changes and significant size of osteophytes. 
Citation: Abdullaeiv RY, Bubnov R, Tsymbalyuk V, Grechanyk O, Kalika L, et al. (2017) Ultrasonography of the Diagnosis the DegenerativeDystrophic Changes in the Vertebral Motor Segment as a Potential Cause of Back Pain: Pictorial Essay . J Spine 6: 394 . doi: 10.4172/2165-7939.1000394

Page 7 of 7

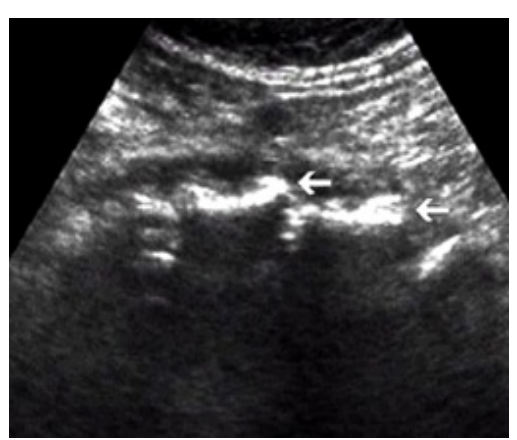

Figure 26: Degeneration of intervertebral discs L3-L4 and L4-L5. Antelies - displacement of bodies of vertebrae forward (arrows).

In the cervical department, osteoarthritis arthrosis is often detected, which is detected in the anterior axial section and leads to compression of the vertebral artery on the side of the lesion. At the same time, its diameter decreases and the brightness of the color signal decreases. Spondyloarthrosis can be diagnosed both from the back and front access (Figure 27).

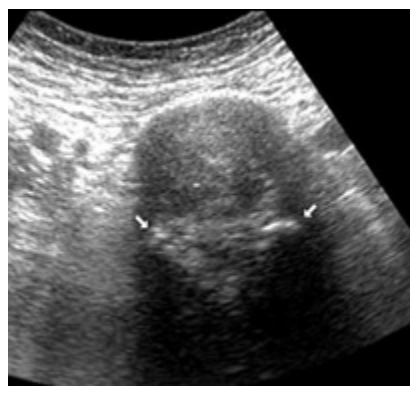

Figure 27: Degeneratrion of the intervertebral disc L5-S1. Arthrosis of facet joints (arrows).

\section{Conclusion}

Thus, ultrasonography is effective for the diagnosis the degenerative-dystrophic changes in the vertebral motor segment as a potential cause for pathophysiological mechanism of back pain.

\section{Acknowledgement}

This article represents the chapter in the following monograph:

R. Ya Abdullaev, R.V. Bubnov, V.I. Tsymbalyuk, O.I. Grechanyk, L. Kalika, Z. Pilecki. Ultrasound of the spine, peripheral nerves and for pain management - Kharkiv: Fact, 2017:172.

\section{References}

1. Abdullaev RY, Ibragimova KN, Kalashnikov VI, Abdullaev RR (2017) The role of b-mode ultrasonography in the anatomical evaluation of the cervical region of the spine in adolescents. J Spine 6: 386.

2. Abdullaeiev RY, Khvisyuk AN, Marchenko VG (2008) Ultrasonic tomography of the vertebral motor segment. New word Publications, Kharkiv, Ukraine.

3. Abdullaev RY, Kalashnikov VI, Ibragimova KN, Mammadov IG, Abdullaev RR (2017) The role of two-dimensional ultrasonography in the diagnosis of protrusion of cervical intervertebral discs in adolescents. Am J Clin Exp Med 5: 176-180.

4. Abdullaev RY, Bubnov RV, Tsymbalyuk VI, Grechanyk OI, Kalika L, et al. (2017) Ultrasound of the spine, peripheral nerves and for pain management - Kharkiv: Fact, pp: 172.

5. Abdullaiev R, Gayko G, Bubnov R, Fodor D, Pilecki Z, et al. (2013) Ultrasonography of the joints. The Manual. Kharkiv: Nove slovo, pp: 152.

6. Abdullaiev RY, Bubnov RV (2012) Diagnostic possibilities of ultrasonography for stenosis of the lumbar vertebral canal. Slovak journal of health sciences: časopis v oblasti výskumu zdravia, zdravotného stavu a liečby chronických ochorení. Trnava 3: 103-104.

7. Abdullaiev RY, Bubnov RV (2012) Ultrasound diagnosis of atlanto-axial rotatory subluxation in neonates. Slovak journal of health sciences: časopis $\mathrm{v}$ oblasti výskumu zdravia, zdravotného stavu a liečby chronických ochorení. Trnava 3: 104-105.

8. Abdullaiev RY, Bubnov RV (2012) Ultrasonographic diagnosis of atlantoaxial junction instability in children 4-6 years. Slovak journal of health sciences: časopis $\mathrm{v}$ oblasti výskumu zdravia, zdravotného stavu a liečby chronických ochorení. Trnava 3: 104-105.

9. Abdullaiev RY, Bubnov RV, Mammadov IG, Abdullaiev RR (2014) Ultrasonography of herniated lumbar discs for screening programs in the late childhood and teenage. EPMA Journal 5: 164.

10. Bubnov RV, Abdullaiev RY, Hrazdira L, Pilecki Z, Pilecki G, et al. (2014) Musculoskeletal ultrasound and pain management. Searching for new biomarkers, challenges and recommendations for education and research. Position paper. In Proceedings of the 12th Congress of International Society for Musculoskeletal Ultrasound (ISMUS) in Szeged, Hungary. 